\title{
A escola segundo alunos do ensino médio de Porto Velho-RO
}

\author{
Diana Campos Fontes \\ Vanessa Aparecida Alves Lima
}

\begin{abstract}
Resumo
Nesta pesquisa procuramos compreender o ponto de vista de alunos do ensino médio da rede pública estadual de Porto Velho (RO) sobre a escola e o processo de aprendizagem tendo como referencial teórico a Psicologia Escolar Crítica. A pesquisa teve por base a aplicação de um questionário em 323 alunos de 04 escolas da Zona Leste da cidade, este era composto de 16 questões com 04 opções de respostas para cada uma das questões. Os resultados apontam para uma escola organizada de forma conteudista, que enfoca as atividades de ensino em aulas expositivas e descontextualizadas das necessidades dos alunos - sejam estas de formação profissional ou exercício da cidadania, aspecto considerado mais importante nas relações dentro da escola pelos alunos. Estes parecem introjetar o estigma de serem os únicos responsáveis pelo processo de aprendizagem, atribuindo ao comportamento e às dificuldades pessoais os problemas escolares.
\end{abstract}

Palavras-Chave: Psicologia Escolar, Ensino Médio, estigma.

\section{The school viewed from high school students' perspective}

\begin{abstract}
In this research, we investigate the point of view of high school students from public schools in Porto Velho (RO), Brazil. Based on School Psychology theories, we focus our work on the school and the learning process. We applied a questionnaire to 323 students from 04 schools in the eastern zone of the city, composed of 16 questions, each with 04 response options. The results point to a content-focused school, which emphasize the activities of lecturing and teaching needs without considering the students context, their professional interests and their citizenship. Students seem to internalize the stigma of being solely responsible for the learning process, attributing the personal problems to problems to difficulties at school.
\end{abstract}

Keywords: School Psychology, secondary education, stigma.

\section{La escuela según alumnos de educación secundaria}

\section{Resumen}

En esta investigación tratamos de comprender el punto de vista de alumnos de Educación Secundaria de la red pública estatal de Porto Velho (RO) sobre la escuela y el proceso de aprendizaje teniendo como referencial teórico la Psicología Escolar Crítica. La investigación tuvo por base la aplicación de un cuestionario para 323 alumnos de 04 escuelas de la Zona Este de la ciudad, compuesto por 16 cuestiones, cada una con 04 opciones de respuestas. Los resultados indican una escuela organizada de forma contenidista, que se centra en actividades de enseñanza en clases expositivas y descontextualizadas de las necesidades de los alumnos - sean estas de formación profesional o ejercicio de ciudadanía, aspecto considerado más importante en las relaciones dentro de la escuela por los alumnos. Estos parecen internalizar el estigma de que son los únicos responsables por el proceso de aprendizaje, atribuyendo al comportamiento y a las dificultades personales los problemas escolares. Palabras Clave: Psicología Escolar, educación secundaria, estigma. 


\section{Introdução}

A Psicologia Escolar na perspectiva crítica defende a importância de se compreender o ponto de vista de todos os atores escolares sobre o cotidiano escolar em suas várias facetas. Compreender como os alunos do Ensino Médio percebem a escola e o processo de aprendizagem é, portanto, um aspecto essencial.

Embora a legislação em vigor referente ao Ensino Médio objetive a formação integral do ser humano, em especial o desenvolvimento de competências para o mundo profissional e acadêmico, nossa experiência no sistema educacional público demonstra que os aspectos previstos na legislação educacional nem sempre estão presentes no cotidiano escolar. No entanto, para compreender efetivamente como isto ocorre - em quais aspectos o sistema se mostra falho e quais propostas educacionais têm sido realizadas - nos propusemos a ouvir um dos atores do cotidiano escolar sobre o assunto: o aluno do Ensino Médio.

Pesquisamos estudantes da rede pública estadual do município de Porto Velho - RO sobre como percebem a escola, o processo de aprendizagem e outros aspectos da vivência na escola.

Fundamentamos a proposta desta pesquisa, bem como seu referencial teórico, na perspectiva crítica da Psicologia Escolar. Esta procura compreender a complexidade do cotidiano e a produção do fracasso com a participação dos atores escolares, assim como os processos de intervenção devem ser discutidos e planejados com estes.

A pesquisa foi realizada por meio de questionários aplicados em 323 adolescentes do Ensino Médio em quatro escolas públicas estaduais da zona leste do município de Porto Velho-RO.

\section{Revisão Teórica}

\section{A legislação}

Neste item, cabe destacar as previsões da legislação referentes à formação do aluno e do adolescente, já que iremos compará-las com a visão dos adolescentes pesquisados.

Vejamos o que está previsto.

As bases norteadoras da legislação educacional e dos direitos das crianças e adolescentes têm suas origens na Declaração de Direitos Humanos (ONU, 2009). Esta possui, entre outros princípios, a garantia do direito ao diálogo e à reflexão. Ressalta o valor da dignidade humana, bem como propõe que todas as nações se esforcem em cumpri-la, defendendo que, por meio do ensino e da educação, seja promovido o direito ao respeito, incentivando a fraternidade, a liberdade de acesso ao serviço público, ao trabalho e à justa remuneração.

As legislações pertinentes à Educação que se pautam neste exercício de cidadania são: a Lei nº. 9394/96, LDB - Lei de Diretrizes e Bases da Educação Nacional (Brasil,
1996), que rege os princípios norteadores de todas as esferas educacionais, e a Lei 8069/90, conhecida como ECA - Estatuto da Criança e do Adolescente (Brasil, 1990), que trata, em suas disposições, da proteção integral à criança e ao adolescente.

No Artigo $4^{\circ}$ da Lei de Diretrizes e Bases da Educação Nacional (Brasil, 1996), são contemplados aspectos objetivos, como obrigatoriedade e gratuidade da oferta de vagas, direito ao material didático-escolar, transporte, alimentação, assistência à saúde e quantidade mínima de insumos para a qualidade de ensino. Os artigos $2^{\circ}$ e $3^{\circ}$ tratam de aspectos subjetivos e citam princípios que inspirariam a educação brasileira, entre eles destacamos: liberdade, solidariedade, respeito, gestão democrática do ensino, valorização da experiência extraescolar e vinculação entre a educação escolar, o trabalho e as práticas sociais.

Os Artigos 37 e 38 preveem o acesso dos alunos que não tiveram oportunidade ou continuidade de estudos no Ensino Fundamental e Médio na idade própria. Anteveem o possível fracasso da educação básica, seja por evasão ou por repetências e cria uma nova modalidade de ensino, a Educação de Jovens e Adultos (EJA). Esta deve considerar as características do alunado, seus interesses, condições de vida e de trabalho, mediante cursos e exames, e é restrita a sujeitos de 15 anos de idade para conclusão do Ensino Fundamental e de 18 anos, no caso de nível médio.

Para o nível médio, a Lei de Diretrizes e Bases da Educação Nacional (Brasil, 1996) prevê os seguintes objetivos: consolidar os conhecimentos adquiridos no nível fundamental; preparação para o trabalho e exercício da cidadania; e aprimoramento da pessoa humana - incluindo a formação ética, desenvolvimento da autonomia intelectual e pensamento crítico, bem como a compreensão dos fundamentos científico-tecnológicos dos processos produtivos, relacionando teoria e prática, em cada disciplina.

Os aspectos previstos na legislação dos processos educacionais e destacados aqui são pontos sobre os quais pretendemos investigar sua pertinência e frequência sob o ponto de vista dos entrevistados.

Os artigos $3^{\circ}$ e $5^{\circ}$ do Estatuto da Criança e do Adolescente (Brasil, 1990) estabelecem os direitos de possibilidades de desenvolvimento integral do adolescente como pessoa e o direito à educação, bem como responsabilizam pessoas e instituições pelas ações, omissões e negligências a estes preceitos. $\mathrm{O}$ artigo 53 esclarece que estes direitos possibilitam ao indivíduo o exercício integral de sua cidadania por meio da qualificação ao trabalho, bem como da igualdade de condições de acesso e direito de ser respeitado pelos educadores.

Construímos, no instrumento de investigação desta pesquisa, mais de uma questão para verificar o ponto de vista dos alunos sobre o aspecto integral e inclusivo da formação durante o Ensino Médio. Também elaboramos questões para investigar a percepção dos alunos sobre a escola e como eles compreendem o processo de aprendizagem durante o Ensino Médio, em especial, sob a perspectiva do desenvolvimento integral que leva o sujeito ao exercício da cidadania, 
qualificação para o trabalho e condições igualitárias de acesso (acesso ao Ensino Superior e ao mercado de trabalho).

As leituras destes documentos, bem como a literatura sobre as políticas públicas educacionais a partir da década de 1990, mostram que, de forma geral, há um discurso de enfrentamento da exclusão social. Por outro lado, as pesquisas e ensaios teóricos das diversas formas de exclusão e preconceito no cotidiano escolar, tais como as realizadas por Collares e Moysés (1996), Espósito (1995), Machado (2003), Machado e Proença, (2004), Moysés (2001), Patto (1984, 1997, 1999, 2005), B. P. Souza (2007), M. P. Souza (2006, 2007), Souza e Silva (2009), nos mostram que há grande distância entre a intenção e a realidade.

Destarte, na legislação, parecem garantidos não só os direitos básicos do ser humano como uma formação abrangente, mas também aspectos físicos específicos do cotidiano escolar, bem como a preparação para a vida laboral e social. A escola tem a responsabilidade de ser, para a legislação e para a sociedade, um dos principais veículos de realização destes objetivos.

Portanto, se vamos investigar com os pesquisados como percebem a escola, precisamos também discutir como a escola tem sido compreendida pela Psicologia Escolar Crítica.

\section{A escola}

Muitos aspectos da escola têm sido descritos como deficitários e problemáticos e, apesar disto, a escola continua "em alta" pelo fato de suprir o atendimento das demandas de formação intelectual e transmissão formal de conteúdo (Justo, 2005). A escola continua sendo considerada como imprescindível para o desenvolvimento do indivíduo e da sociedade.

Porém a escola, tal como está estruturada, enfrenta sérios obstáculos para lidar com as demandas do sujeito contemporâneo. A forma como se encontra organizada, com suas disciplinas e aulas, representa um tempo lógico-pedagógico completamente defasado da temporalidade da vida imposta pelo mundo atual, acelerado. As camadas mais pobres não podem esperar pelos morosos conhecimentos escolares para buscar a sobrevivência, e as mais abastadas têm acesso imediato à internet e a outras fontes de informações de que necessita (Justo, 2005).

Surge uma escola pobre para uma clientela pobre: faltam livros, faltam carteiras, faltam professores, faltam atividades criativas, mas, mesmo assim, a culpa do baixo rendimento é da criança. Por outro lado, surge uma escola rica para a clientela que pode pagar pelo conhecimento: os livros e atividades se diversificam, existem laboratórios de informática, os professores estudam. A desigualdade se afirma e a Psicologia subsidia o mérito, que vem justificar o baixo desempenho escolar/social através da identificação de uma natureza desigual dos homens. (Ceccon, Oliveira, \& Oliveira, 1982; Fernandes e cols., 2006; Harper, Ceccon, Oliveira, \& Oliveira, 1987; Patto, 1999, 2005).
No atual sistema educacional, em que encontramos escolas públicas e particulares, as situações de desigualdade no acesso ao conhecimento entre pobres e ricos (Ceccon e cols., 1982; Harper e cols., 1987; Espósito, 1995; Collares \& Moysés, 1996; Patto, 1997, 1999, 2005) pode ser compreendida quando se consideram classes sem professores, ensino automático e monótono, rotulação e não oferecimento de insumos básicos (Patto, 1997), rotatividade de educadores (B. P. Souza, 2007), excessivo número de alunos, ampla variação de idade, ambiente pobre de estimulação, numerosa incidência de repetentes (Barreto, 1984), sobrecarga da jornada de trabalho dos professores, má formação profissional, salários indignos e baixo reconhecimento social (Marinho-Araújo \& Almeida, 2005), entre outros fatores.

E mais, mesmo no sistema educacional privado, encontramos propostas pedagógicas conteudistas (Freire, 1997), tecnicistas e preocupadas apenas com a produção da informação e não com a construção do conhecimento, mas isto se revela especialmente no sistema educacional público, pois a realidade denuncia que a escola atual é uma escola preparada para lidar com classes homogêneas, com pedagogias infantilizadas e descontextualizadas para o adolescente de classes populares (Moysés, 2001; Patto, 1984; B. P. Souza, 2007; M. P. Souza, 2006, 2007; Souza \& Silva, 2009).

O conhecimento é estático. A escola promove a instauração de relações entre os homens, as coisas e os acontecimentos que tendem a produzir modos de ser e viver destituídos de autonomia. O poder de intervir dos sujeitos é constantemente empurrado para fora do campo instituído de produção do conhecimento, configurando um processo que visa conceber atores sociais despotencializados. (Fernandes e cols., 2006).

É comum os alunos tornarem-se os ditos copistas: crianças e jovens capazes de fazer cópias de longos textos com perfeição e capricho, sem que consigam ler o que escreveram. A cópia permite tanto a dissimulação do aluno e do docente quanto do exercício adequado dos seus papéis (Santos, 2008; B. P. Souza, 2007).

Em pesquisas, analisando o ambiente escolar, Patto (2005, p.19) denuncia o mesmo fato:

\footnotetext{
Todos sabem que anos e anos de uma política educacional que tem na base o descaso pela boa qualidade da escola para o povo, num país extremamente desigual do ponto de vista socioeconômico e secularmente marcado pelo cinismo diante dos direitos dos cidadãos, acabaram por instalar nas escolas uma dinâmica, muitas vezes difícil e até mesmo cruel, que traz danos diários a todos os envolvidos no processo: técnicos, administradores, professores, funcionários, alunos e famílias usuárias da escola.
}

As possibilidades antagônicas e contraditórias tecida pelos desafios presentes nas formas de trabalhar e de viver desdobram-se no resgate do significado das próprias ações, singulares ou coletivas, que fazem da atividade e do discurso presente no espaço de trabalho possibilidades de 
conhecimento e reconhecimento de si, do outro e do mundo. (Marinho-Araújo \& Almeida, 2005).

Nesta perspectiva, nosso instrumento de pesquisa também procurou verificar como os alunos percebem esta realidade no cotidiano, no processo de aprendizagem e durante a formação escolar. Esquadrinhamos questões que nos levassem a compreender como os alunos veem o processo de inclusão/exclusão produzido pelo sistema educacional por meio da aprendizagem, seja nos conteúdos ou nas estratégias pedagógicas.

E qual tem sido a participação da Psicologia nesta instituição, a escola?

\section{Psicologia Escolar Crítica}

A Psicologia Educacional tradicional considera o desenvolvimento do psiquismo como de natureza biológica, e nesta perspectiva podemos identificar a manifestação de uma das características da lógica formal, a abordagem empírica do pensamento. Esta abordagem defende que a autêntica fonte e a base da formação dos conceitos estão nas próprias coisas e objetos naturais, como se a mera experiência direta com os objetos fosse suficiente para formar os conceitos. Tal compreensão traduz-se, nos sistemas escolares, em uma estruturação tradicional dos programas de estudo (Araújo \& Moura, 2003).

Justamente por compreender a influência de tais correntes de pensamento, entre outras, na formação dos profissionais do saber psicológico no Brasil durante muitos anos, Collares e Moysés (1996), Machado (2003), Machado e Proença (2004), Moysés (2001), B. P. Souza (2007) e M. P. Souza $(2006,2007)$ consideram que a atuação dos psicólogos na escola baseou-se em um modelo clínico de atendimento ao escolar fortemente marcado por uma prática psicodiagnóstica, psicométrica, psicoterapêutica e reeducativa, centrada em um referencial positivista de ciência e em uma visão do aluno centrada na teoria da carência cultural.

Por isto, a discussão contemporânea da Psicologia Escolar Crítica ressalta a necessidade da Psicologia Escolar/Educacional rever seu objeto de estudo, seus métodos e finalidades, bem como a necessidade de se buscar novas possibilidades de conceituação da área e para a atuação do psicólogo escolar/educacional (Araújo \& Moura, 2003; Meira, 2003; Tanamachi \& Meira, 2003). Estas propostas têm se concretizado a partir da década de 1980.

Tais ideias demonstram a existência de um movimento de superação de modelos psicológicos tradicionalmente utilizados no âmbito escolar e educacional, buscando formas de aproximação com a escola ou com a instituição educacional - quer na pesquisa, quer na atuação profissional - coerentes com a concepção de homem e de mundo referenciadas em uma perspectiva crítica em Educação e Psicologia (Meira, 2003; Vectore \& Maimoni, 2007).

Nesta perspectiva, a Psicologia se propõe a explicar como, a partir do mundo objetivo, se constrói o mundo subjetivo do indivíduo. O papel do psicólogo em uma instituição de ensino seria então o de promover o encontro entre os sujeitos e a educação, tendo como finalidade central a construção de um processo educacional que seja capaz de socializar o conhecimento historicamente acumulado e de contribuir para a formação ética e política do sujeito por meio da construção de práticas educativas que favoreçam processos de humanização e reapropriação da capacidade de pensamento crítico (Tanamachi \& Meira, 2003).

A Psicologia Escolar Crítica, diante das transformações sociais e culturais, pode auxiliar os agentes educativos e os alunos a conviverem com a as diferenças, contradições e ambiguidade presentes no cotidiano escolar (Novaes, 2001).

Este aspecto determina que a proposta crítica da Psicologia Escolar leve em conta os processos históricos de forma macro na construção do pensamento e do sistema educacional, e de forma micro na produção dos históricos escolares de cada sujeito (M. P. Souza, 2006, 2007).

Uma das formas de contribuir para a humanização das relações escolares é a escuta dos atores escolares. Há relevância na escuta da versão do aluno e de sua experiência escolar, valorizando sua condição de sujeito da própria história, percebendo suas necessidades, sofrimentos e dificuldades, e possibilitando a reflexão (B. P. Souza, 2007) não só para compreender o cotidiano escolar, mas especialmente para uma proposta de atuação/intervenção, que deve sempre partir da observação constante das rotinas institucionais, bem como de um diálogo frequente com os alunos e profissionais envolvidos no trabalho. (Vectore \& Maimoni, 2007).

O psicólogo escolar deve ajudar a escola a remover obstáculos que se interpõem entre os sujeitos e o conhecimento e a formar cidadãos por meio da construção de práticas educativas que favoreçam processos de humanização e reapropriação da capacidade de pensamento crítico (Tanamachi \& Meira, 2003) não só por meio de seu trabalho dentro da escola, mas também por meio da produção de conhecimento, com pesquisas que possam esclarecer a complexidade do cotidiano escolar, inclusive das relações que ali se estabelecem.

\section{Abordagem Metodológica}

Utilizamos, nesta pesquisa, o método quantitativo, pois entendemos que "as abordagens quantitativas se conformam melhor à investigações de grupos e segmentos delimitados e focalizados" (Minayo, 2008, p. 57). Nesta ótica, procuramos abranger um número considerável de alunos do Ensino Médio da rede pública estadual do município de Porto Velho (RO), utilizando como suporte pertinente a produção científica na área de Psicologia (Scarparo, 2008).

\section{Instrumento da pesquisa}

O instrumento utilizado foi um questionário com dezesseis questões com quatro opções de resposta cada. As questões do questionário são as seguintes: 
1. Em sua opinião, o que é mais importante na escola? Eventos / Amigos / Aulas / Esporte

2. Entre as atividades escolares, qual você acha mais importante? Explicação do professor / Provas / Pesquisa e trabalhos / Exercícios

3. Em sua opinião, o que você aprende na escola você usa no seu dia a dia? Sempre / Às vezes / Raramente / Nunca

4. Você acha que as disciplinas estão de acordo com as necessidades do aluno? Sempre/ Às vezes / Raramente / Nunca

5. Você gosta de vir à escola? Sempre / Às vezes / Raramente / Nunca

6. Se hoje você pudesse escolher entre vir ou não vir para escola, e isto não trouxesse nenhum prejuízo para você, o que você preferiria? Vir mesmo assim / Vir de vez em quando para ter presença / Vir apenas quando gostasse da aula / Nunca vir

7. Em sua opinião, por que muitos alunos não concluem o nível médio no ensino regular? Atrasados ficam desanimados / Desistem / Demora muito / É difícil passar

8. Qual a principal vantagem do Ensino Médio regular para o aluno? Melhor base para vestibular / Profissionalização / Acabar na idade certa / Mais conteúdo e mais devagar

9. Em sua opinião, o que proporciona qualidade na escola? As pessoas (alunos, funcionários) / Estrutura física / Bons funcionários / Material didático

10. Qual o maior problema da sua escola hoje? Comportamento dos alunos / Falta de funcionários / Falta de material / Dificuldades nas matérias

11. Qual o maior benefício que a escola tem dado aos alunos? Conhecimento / Relacionamentos / Oportunidade profissional / Oportunidade para continuar estudando

12. No que diz respeito a seu relacionamento com os professores, como você se encaixaria? Ótimo / Bom / Regular / Ruim

13. No que diz respeito à metodologia de ensino, como você classificaria as aulas do nível médio? Ótimo / Bom / Regular / Ruim

14. Como você se sente em relação ao seu rendimento (notas e médias)? Só tiro notas boas / Tenho algumas dificuldades, mas dá para passar / Precisa Melhorar / Não sei se consigo passar

15. Você acha que a escola de hoje é uma escola de qualidade? Sempre / Às vezes / Raramente / Nunca

16. Ao concluir o nível médio, você pretende? Educação superior / Trabalhar em empresa privada / Ser aprovado em concurso público / Fazer um curso profissionalizante

As questões tentaram contemplar os aspectos do cotidiano escolar e sua representatividade para os alunos, abordando temáticas como atividades escolares, uso do aprendizado escolar no cotidiano, vantagens de cursar o nível médio na modalidade regular, evasão escolar, metodologia de ensino e perspectivas após a conclusão do Ensino Médio.

\section{Locais do estudo}

Para a escolha das escolas participantes da pesquisa, fizemos o procedimento que será descrito a seguir. Considerando que a rede estadual de ensino é a responsável pelo Ensino Médio, relacionamos as escolas pertencentes a esta e focalizamos instituições em que tal oferta se desse no período diurno na forma regular, não só pela disponibilidade de pesquisadoras e pesquisandos, mas também para compreender o processo sem variantes de faixas etárias ou na condição da Educação de Jovens e Adultos.

Como pretendíamos pesquisar alunos que residissem nas imediações das escolas, escolhemos como alvo as escolas da zona leste do município de Porto Velho (existem no município três zonas que caracterizam regiões econômicas com polo comercial e governamental de acesso à população, a zona central, a zona leste e a zona sul - estas duas últimas consideradas com uma parte central e outra periférica).

A zona leste possui 05 escolas que se enquadraram no perfil pretendido e que passaram a ser o local da pesquisa. Estas escolas, preservando o sigilo e a ética, passarão aqui a ser denominadas Escola 1, Escola 2, Escola 3, Escola 4 e Escola 5.

\section{População pesquisada}

Os participantes da pesquisa foram unicamente alunos do Ensino Médio da rede pública estadual. A participação foi autônoma; nas salas de aula, acompanhadas das supervisoras ou diretoras, apresentávamos o trabalho e perguntávamos quem gostaria de participar. Houve grande disponibilidade por parte dos alunos, já que muitos queriam participar. Não achamos necessário nenhuma distinção de sexo ou idade neste procedimento, pois, sendo alunos do Ensino Médio regular em curso diurno, encontramos entre eles a faixa etária esperada para o ano, logo os participantes tinham aproximadamente entre 14 e 19 anos. Quanto ao sexo, não foi nosso foco nesta pesquisa que não traz referenciais de gênero.

Sabemos da importância de compreender o ponto de vista de todos os atores escolares, embora, neste momento, tenhamos procurado compreender o ponto de vista dos alunos; em novas pesquisas, buscaremos o ponto de vista dos demais, como professores e gestores. 
A clientela escolar total atendida no Ensino Médio pelas 05 escolas era, no ano de 2008, quando desenvolvemos a pesquisa, de 1.190 alunos. Com apoio de um especialista em Estatística, definimos como quantitativo significativo de amostra $1 / 4$ da população, ou seja, aproximadamente 300 questionários. Dividimos a quantidade de questionários proporcionalmente à quantidade de alunos de cada escola, com o objetivo de pesquisar $1 / 4$ da clientela. Não houve distinção de idade ou sexo na escolha dos participantes.

Na Escola 1 estavam matriculados 412 alunos no Ensino Médio e, nesta, ficou definida a aplicação de 105 questionários, representando $35 \%$ da amostra total a ser pesquisada por nós. E assim, sucessivamente: Escola 2: 41 matriculados, 11 questionários - 3,67\% da amostra; Escola 3: 374 matriculados, 95 questionários - 31,67\% da amostra; Escola 4: 280 matriculados, 71 questionários - 23,67\% da amostra; Escola 5: 83 matriculados, 18 questionários - 6\% da amostra. Esta distribuição totalizou 1.190 alunos matriculados, 300 questionários e $100 \%$ da amostra.

\section{Procedimentos}

Para o envio do projeto ao Comitê de Ética na Pesquisa, obtivemos cartas de autorização da secretária de Estado da Educação e das diretoras das escolas selecionadas. Houve um hiato de 03 meses entre a obtenção das autorizações e o início da pesquisa. Quando iniciamos a pesquisa, a diretora da Escola 5 havia sido substituída e a nova diretora se recusou a participar. Assim, o número de alunos previstos para serem pesquisados na Escola 5 foi dividido proporcionalmente entre as demais escolas. Desta forma, na análise dos dados, não faremos referência à Escola 5 .

Sabendo das dificuldades na devolução dos Termos de Consentimento Livre e Esclarecido, pois os alunos os levam para consentimento dos pais ou responsáveis em casa, mas não os devolvem, resolvemos entregar aproximadamente $20 \%$ a mais de TCLEs aos alunos que estavam dispostos a participar voluntariamente do estudo. Destes, obtivemos 323 TCLEs assinados e, portanto, resolvemos aplicar o questionário em todos. Logo, nossa amostra excedeu o estipulado. Partimos, então, de 323 questionários para o cálculo dos percentis na análise de dados.

\section{Apresentação e Análise dos Resultados}

Com a quantificação das respostas efetuadas por questão, calculamos a porcentagem utilizando a fórmula abaixo, na qual $\mathrm{P}=$ porcentagem, $\mathrm{n}=$ número, $\mathrm{A}=$ amostra $\mathrm{e}$ $\mathrm{S}=$ tamanho da população total pesquisada ${ }^{1}$.

1 Sendo esta pesquisa originalmente uma monografia de conclusão de curso de Especialização em Psicologia Escolar, analisamos cada questão individualmente, compondo um gráfico de setores para cada uma delas. Considerando o formato deste artigo científico, faremos apenas o comentário de cada questão, sem apresentar os
A questão 1 procurou investigar o que os alunos consideravam mais importante na escola, se seriam eventos, amigos, aulas ou esporte. A maioria dos alunos (67\%) optou por responder que são as aulas, significado que poderia ser interpretado como politicamente correto e do histórico significado de "ir para a aula" como sinônimo de ir à escola. Contudo, nesta questão, não se pode desprezar os $22 \%$ que consideram mais importante na escola os seus amigos.

Chama a atenção o fato de que apenas $8 \%$ considerem os esportes algo importante na escola, pois se concebemos a proposta da LDB (Brasil, 1996) de exercício da cidadania, compreensão dos fundamentos científicos tecnológicos e relação de teoria e prática em cada disciplina, não é difícil entender a importância que têm as atividades esportivas nesta formação. O que implica que apenas $8 \%$ tenham citado o esporte como importante na escola? Não tememos responder que é a forma como a atividade esportiva vem sendo desenvolvida nas escolas, mais como um prêmio ou castigo do que como um item de formação integral do indivíduo. Entre as 04 escolas da pesquisa, apenas duas têm espaço para atividades esportivas. Então onde ocorrem as aulas de Educação Física? Nas salas de aula, de forma teórica.

A questão 2 aborda qual atividade escolar é considerada pelo aluno como mais importante. Tal questionamento revelou que $59 \%$ dos alunos consideram a explicação do professor, ou seja, aulas expositivas, e que $28 \%$ dos alunos consideram pesquisas e trabalhos mais importantes. Tais dados revelam a centralização das atividades escolares em aulas expositivas, com a tímida, mas considerável resposta para aprendizagem autônoma dos alunos, com um papel mais ativo do estudante.

A organização conteudista do ensino (Freire, 1997) centralizada em aulas expositivas chega mesmo a convencer o aluno de que esta é a melhor forma de aprender. Até mesmo porque as fontes de pesquisa são escassas - neste caso, a melhor biblioteca da cidade, que é a Biblioteca Municipal, fica no centro da cidade, pelo menos a $10 \mathrm{~km}$ das escolas pesquisadas. Precisamos perceber no que isto implica. A estrutura conteudista dos programas de estudo (Marinho-Araújo \& Almeida, 2005) pode destituir de autonomia os sujeitos que se formam na escola (Fernandes e cols., 2006). Neste aspecto, temos que nos perguntar se isto não é um processo ideológico do capitalismo na formação de mão de obra desqualificada e de baixo custo (Ceccon e cols., 1982; Harper e cols., 1987).

Na questão 3, $75 \%$ dos alunos consideram que os conteúdos escolares não são importantes para o dia a dia. Este dado concorda com os resultados da questão 4 , em que somente $23 \%$ consideram que as informações e conhecimentos de sala de aula atendem suas necessidades. A forma como o aluno percebe seu processo de aprendizagem no Ensino Médio está explícita nestes dados, que são também corroborados pela questão 8 . Nesta, $73 \%$ dos alunos compreendem que o Ensino Médio serve, na verdade, para

gráficos. Contudo, as autoras disponibilizam aos interessados, caso solicitado por e-mail, todos os gráficos e seus comentários. 
dar base para o vestibular, ou seja, o Ensino Médio não tem se revelado como uma formação para a vida, mas apenas como um meio, uma fase, um período. Estes dados demonstram que a formação do cidadão não tem sido contemplada no processo de aprendizagem de alunos do Ensino Médio, nem no aspecto da preparação para o trabalho e tampouco no exercício da cidadania.

Mas, do objetivo conteudista a que parecem se dedicar as escolas pesquisadas, de dar informação para que os alunos consigam atingir o Ensino Superior, das quatro escolas pesquisadas, os alunos de duas delas têm obtido bom índice de aprovação em faculdades públicas e privadas do município de Porto Velho (RO).

A escola é um "meio" para outras situações e não tem, do ponto de vista dos alunos participantes da pesquisa, contribuído para a consciência e ação do cidadão no momento presente da formação. Estes dados das questões 3, 4 e 8 são complementados com os dados da questão 11, na qual $39 \%$ apontam a escola como um meio essencial para se alcançar outros fins (oportunidades profissionais - $22 \%$ e prosseguimento dos estudos - 17\%). E, ainda, os dados da questão 15, na qual os alunos afirmam que só eventualmente $(45 \%)$ e raramente $(27 \%)$ a escola é de qualidade (para suas necessidades).

Considerando os dados das questões 3 e 4 (acima), devemos compreender a resposta dos alunos à questão 5 pelo viés da socialização, já que $57 \%$ respondem que sempre gostam de vir à escola e $40 \%$ que gostam às vezes. Ora, se veem na escola de Ensino Médio um ambiente que não supre suas necessidades e que não tem relação com o cotidiano, por que frequentá-la? Pelas relações sociais que ela possibilita. Esta situação fica comprovada com as respostas da questão 9 , na quais $72 \%$ consideram que a qualidade da escola de Ensino Médio está nos relacionamentos. Então a escola cumpre uma função social, que pode até realizar os objetivos de formação para o exercício da cidadania, como prevê a LDB (Brasil, 1996), mas isto não é resultado de um projeto, mas de uma situação, de um ambiente.

$\mathrm{Na}$ questão $6,37 \%$ dos alunos revelam que nem sempre gostam das aulas dadas e por isto não viriam às aulas se pudessem. Este dado é revelador, pois, na questão 7, $48 \%$ dos entrevistados apontam que os alunos simplesmente desistem do Ensino Médio. A falta de prazer em frequentar a escola, somada ao fato de que os conteúdos escolares no Ensino Médio não são vistos como úteis, parece levar, na compreensão dos alunos pesquisados, à desistência. Collares e Moysés (1996), Machado (2003), Machado e Proença (2004), Moysés (2001) e M. P. Souza (2006, 2007), conhecem bem e nos apresentam, nos relatos de suas pesquisas, a realidade de desistência que ocorre nas escolas públicas. Estas autoras nos auxiliam a compreender que não é o aluno que desiste ou evade, mas que, na verdade, é o sistema educacional que os expulsa. Quando $10 \%$ dos alunos pesquisados dizem que viriam para a escola apenas de vez em quando para ter presença, mas que $37 \%$ viriam sempre se gostassem das aulas, precisamos concordar com Justo (2005), o qual considera que a escola está em um tempo lógico-pedagógico defasado da temporalidade do mundo atual, por isto ela não tem sido fonte de prazer para os alunos, especialmente os do Ensino Médio, que são adolescentes.

E, apesar de terem consciência de toda esta problemática relacionada à escola de Ensino Médio, ao serem perguntados sobre onde está a problemática principal da escola, as respostas são autorresponsabilizadoras, ou seja, o aluno compreende que, se a escola vai mal, a responsabilidade é deles mesmos. Portanto, apontam como problemas da escola as dificuldades nas matérias (43\%) e os comportamentos dos alunos (33\%), revelando uma compreensão de aluno ideal introjetada, na qual caberia a este o papel de saber se comportar e ter facilidade nas matérias.

Interessante é que, como adolescentes conscientes de sua realidade, conseguem apontar que os problemas da escola também podem estar na falta de funcionários (11\%), na falta de materiais (13\%) e na falta de material didático (23\%), mas ainda predomina o estigma introjetado de que, se a escola vai mal, são os alunos (e consequentemente seus familiares) que estão mal (Collares \& Moysés, 1996).

Isto é corroborado com os dados das questões 12, 13 e 14. Na questão 14, 65\% dos alunos consideram que possuem dificuldades para aprender e outros $25 \%$ consideram que precisam melhorar $(90 \%$ dos alunos se consideram insatisfeitos com seu rendimento), mas não veem esta dificuldade fora de si, pois $51 \%$ consideram o relacionamento com os professores bom (questão 12) e 49\% consideram adequada a metodologia de ensino (questão 13). Ora, se a melhoria do processo de aprendizagem não está, segundo estes alunos, nem no relacionamento com os professores, nem na metodologia do ensino, isto implica que compreendem os problemas da escola como responsabilidade sua, ou seja, identificam-se com a cristalização do estereótipo de não aprender sob responsabilidade do aluno (Freller, 2004; Meira, 2003; Collares \& Moysés, 1996).

\section{Considerações Finais}

A pesquisa não objetivou verificar o papel do psicólogo escolar neste processo, mesmo porque temos conhecimento de que não há um psicólogo na escola, mas continuamos acreditando que o psicólogo escolar poderia contribuir substancialmente com as situações aqui descritas. Isso poderia ocorrer se o psicólogo pudesse atuar na perspectiva que teorias da Psicologia Escolar, como as de Marinho-Araújo e Almeida (2005), M. P. Souza (2006, 2007), Tanamachi e Meira (2003) e Vectori e Maimoni (2007), têm descrito, promovendo o diálogo sobre o cotidiano escolar, trabalhando em grupos, possibilitando a convivência da complexidade.

O psicólogo é essencial nas escolas para incentivar o diálogo entre os alunos e demais atores escolares por meio da escuta mútua, potencializando uma maior compreensão de diferentes pontos de vista. Uma escola com maior comunicação contribuiria na busca por uma educação integral 
do ser humano e na formação de cidadãos, como defende a LDB (Brasil, 1996), condições que são um grande passo para uma sociedade mais justa e que ofereça melhores condições de vida para toda a população.

Para nós, não só o ponto de vista dos alunos sobre a aprendizagem e o cotidiano escolar é importante, mas há valor na compreensão da versão de outros segmentos que compõem a comunidade escolar. Por razões metodológicas e institucionais, discutimos aqui o ponto de vista dos alunos, mas cremos que novas pesquisas devam ampliar a compreensão desta percepção para o ponto de vista dos professores, gestores e outros educadores, especialmente no Estado de Rondônia e demais Estados da Região Norte do Brasil, ainda tão carentes de dados específicos sobre suas realidades.

\section{Referências}

Araújo, E. S., \& Moura, M. O. (2003). A aprendizagem docente na perspectiva histórico-cultural. Programa de Pós-Graduação da Faculdade de Educação da Universidade de São Paulo.

Barreto, E. S. S. (1984). Professores de periferia: soluções simples para problemas complexos. Em M. H. S. Patto, Introdução a Psicologia Escolar (pp. 329-355). São Paulo: Casa do Psicólogo.

Ceccon, C., Oliveira, M. D. de, \& Oliveira, R. D. de. (1982). A vida na escola e a escola da vida (5a. edição). Petrópolis, RJ: Vozes.

Collares, C. A. L., \& Moysés, M. A. A. (1996). Preconceitos no cotidiano escolar: ensino e medicalização. São Paulo: Cortez.

Espósito, V. H. C. (1995). O que é isto, a escola? Em R. V. Serbino \& M. A. R. L. Grande, A escola e seus alunos: o problema da diversidade cultural (pp. 115-120). São Paulo: UNESP.

Fernandes, A. M. D., Moura, A. A., Sousa, D. M. F., Patriota, G. F., Araújo, J. M. A., França, M. L. P. e cols. (2006). Histórias e práticas do sofrer na escola: múltiplos atos/atores na produção do "alunoproblema”. Em A. M. Machado \& A. M. Fernandes (Orgs.), Novos possíveis encontros da Psicologia com a Educação (pp. 145-166). São Paulo: Casa do Psicólogo.

Freire, P. (1997). Educação "bancária" e educação libertadora. Em M. H. S. Patto, Introdução à Psicologia Escolar (3a. edição, pp. 61-78). São Paulo: Casa do Psicólogo.

Freller, C. C. (2004). Crianças portadoras de queixa escolar: reflexões sobre o atendimento psicológico. Em A. M. Machado \& M. Proença (Orgs), Psicologia escolar: em busca de novos rumos (pp. 67-81). São Paulo: Casa do Psicólogo.

Harper, B., Ceccon, C., Oliveira, M. D., \& Oliveira, R. D. (1987). Cuidado Escola! Desigualdade, domesticação e algumas Saídas (7a edição). São Paulo: Brasiliense.
Justo, J. S. (2005). Escola no epicentro da crise social. Em Y. de La Taille, Indisciplina/disciplina: ética, moral e ação do professor. Porto Alegre: Mediação.

Lei 9.394 de 20 de dezembro de 1996. (1996). Lei de diretrizes e Bases da Educação Nacional. Diário Oficial da União, seção 1. Recuperado: 31 mai 2008. Disponível: http://portal.mec.gov.br.

Lei 8.069, de 13 de julho de 1990. (1990). Estatuto da Criança e do Adolescente. Diário Oficial da União. Recuperado: 31 mai 2008. Disponível: http://www.planalto.gov.br.

Machado, A. M. (2003). Os psicólogos trabalhando com a escola: intervenção a serviço do quê? Em M. E. M. Meira \& M. A. M. Antunes (Orgs), Psicologia Escolar: teorias críticas (pp. 63-85). São Paulo: Casa do Psicólogo.

Machado, A. M., \& Proença, M. (2004). As crianças excluídas da escola: um alerta para a psicologia. Em A. M. Machado \& M. Proença (Orgs.), Psicologia Escolar: em busca de novos rumos (pp. 39-54). São Paulo: Casa do Psicólogo.

Marinho-Araújo, C. M., \& Almeida, S. F. C. (2005). Psicologia escolar: construção e consolidação da identidade profissional. Campinas, SP: Alínea.

Meira, M. E. M. (2003). Construindo uma concepção crítica de psicologia escolar: contribuições da pedagogia histórico-crítica e da psicologia sociohistórica. Em M. E. M. Meira \& M. A. M. Antunes (Orgs.), Psicologia escolar: teorias críticas (pp. 13-77). São Paulo: Casa do Psicólogo.

Minayo, M. C. S. (2008). O desafio do conhecimento: pesquisa qualitativa em saúde. (11a edição). São Paulo: Hucitec.

Moysés, M. A. A. (2001). A institucionalização invisível: crianças que não aprendem na escola. Campinas, SP: Mercado das Letras.

Novaes, M. H. (2001). Perspectivas para o futuro da psicologia escolar. Em S. M. Wescheler (Org.), Psicologia escolar: pesquisa, formação e prática (pp. 61-71). Campinas, SP: Alínea.

Organização das Nações Unidas no Brasil (ONU). (2009). Declaração dos Direitos Humanos. Recuperado: 24 mai 2009. Disponível: http://www.onu-brasil.org.br/documentos.

Patto, M. H. S. (1984). Psicologia e ideologia: uma introdução crítica à psicologia escolar. São Paulo: T. A. Queiroz.

Patto, M. H. S. (1997). A família pobre e a escola pública: anotações sobre um desencontro. Em M. H. S. Patto, Introdução a Psicologia Escolar (pp. 281-296). São Paulo: Casa do Psicólogo.

Patto, M. H. S. (1999). A produção do fracasso escolar: histórias de submissão e rebeldia. São Paulo: Casa do Psicólogo. 
Patto, M. H. S. (2005). Exercícios de indignação: escritos de educação e psicologia. São Paulo: Casa do Psicólogo.

Santos, A. A. C. (2008). Cadernos e outros registros escolares da primeira etapa do ensino fundamental: um olhar da psicologia escolar crítica. Tese de Doutorado, Instituto de Psicologia da Universidade de São Paulo, São Paulo.

Scarparo, H. (Org.). (2008). Psicologia e pesquisa (2a edição). Porto Alegre: Sulina.

Souza, B. P. (2007). Apresentando a orientação a queixa escolar. Em B. P. Souza (Org.), Orientação à queixa escolar (pp. 97-117). São Paulo, Casa do Psicólogo.

Souza, B. P. (2007). Funcionamentos escolares e produção de fracasso escolar e sofrimento. Em B. P. Souza (Org.), Orientação à queixa escolar (pp. 241-278). São Paulo, Casa do Psicólogo.

Souza, M. P. R. (2006). Políticas Públicas e Educação: desafios, dilemas e possibilidades. Em L. Viegas \& C. B. Angelucci (Orgs.), Políticas Publicas em Educação: uma análise crítica a partir da Psicologia Escolar (pp. 229-243). São Paulo: Casa do Psicólogo.
Souza, M. P. R. (2007). Prontuários revelando os bastidores do atendimento psicológico à queixa escolar. Em B. P. Souza (Org.), Orientação à queixa escolar (pp. 27-58). São Paulo, Casa do Psicólogo.

Souza, M. P. R., \& Silva, S. M. C. (2009). A atuação do psicólogo na rede pública de educação frente à demanda escolar: concepções, práticas e inovações. Em C. M. Marinho-Araújo (Org.), Psicologia escolar: novos cenários e contextos de pesquisa, formação e prática (pp. 75-105). Campinas, SP: Alínea.

Tanamachi, E. R., \& Meira, M. E. M. (2003). A atuação do psicólogo como expressão do pensamento crítico em psicologia e educação. Em M. E. M. Meira \& M. A. M. Antunes (Orgs.), Psicologia escolar: práticas críticas (11-62). São Paulo. Casa do Psicólogo.

Vectore, C., \& Maimoni, E. H. (2007). A formação do psicólogo escolar e a atuação em instituições infantis: da história às práticas atuais. Em H. R. Campos (Org.), Formação em Psicologia Escolar, realidades e perspectivas (pp. 135-147). São Paulo: Alínea.
Recebido em: 05/07/2010

Reformulado em: 24/05/2011

Aprovado em: 03/06/2011

\section{Sobre as autoras}

Diana Campos Fontes (fontesdiana12@hotmail.com)

Psicóloga Escolar da Secretaria de Estado de Educação (SEDUC/RO) e Coordenadora da Educação Especial nas escolas da Rede Estadual de Ensino no município de Porto Velho. Especialista em Psicologia Escolar (UNIR, 2009); Especialista em Terapia de Família (Candido Mendes, 2002); Graduada em Psicologia (UNIR 2000).

Vanessa Aparecida Alves Lima (limavanessa@uol.com.br)

Docente do Mestrado Acadêmico em Psicologia/UNIR (Universidade Federal de Rondônia) e do DEPSI/UNIR. Doutora e Mestre em Psicologia pelo IP/USP. Formada em Psicologia e Licenciada em Geografia pela UNIR.

\section{Correspondência}

Rua dos Sonhos, 2711. Residencial Forte Príncipe. Bairro Costa e Silva. Porto Velho (RO). CEP 76.803-510. (69) 9984-0449. 